THORNICROFT, G. (1994) The NHS and Community Care Act. 1990. Recent government policy and legislation. Psychlatric Bullettr. 18, 13-17.

WARD. P. (1994) The mental health market. Recent government policy and legislation. Psychiatric Bulletin, 18, 538-540.
Sara Davies, Sentor Registrar, Maudsley Hospital, Denmark Hill, London SE5 8AZ; and Edward Peck, Director, Centre for Mental Health Services Development, Kings College London, Campden Hill Road, Kensington, London W8 7AH

\title{
Rescinding responsibilities as nearest relative and displacing the nearest relative
}

\author{
Fiona Cooke, Julia Watkins and Clive Adams
}

\begin{abstract}
A case report is presented which highllghts two importont, but rarely evoked, aspects of mental health low. In this case, the mentally in person's nearest relative did not with to act as such and rescinded his responsiblitty in fovour of another. This other person cblected to the use of section 3 of the Mental Heatth Act 1983 and clisplacement of her as nearest relative was considered. some cases from the liferature are clied to help clatily the meaning of "unreasonable objection" as used in the Mental Hectith Act 1983.
\end{abstract}

\section{Case}

Mr $\mathrm{AB}$ is a middle-aged man with a long history of psychotic episodes characterised by delusions and hallucinations. These symptoms have been responsive to medication but $\mathrm{Mr} A B$ has never been compliant with treatment for any significant period. He arrived on the ward very threatening and aggressive and was obviously deluded and hallucinated. Since $\mathrm{Mr}$ AB was well known to the services, the psychiatric team felt that section 3 of the Mental Health Act (1983) was appropriate.

Mr AB's parents live apart. His father is the older of the two and, therefore, legally is the nearest relative. Mr AB's mother, however, was much more involved in his care so she was contacted regarding the use of section 3 . She was adamant that this was inappropriate and felt that her son was not suffering from a mental lllness. She believed that any medication would be both addictive and harmful. The team persuaded her that to help her son's mental dis order, and to come to a compromise, section 2 should be applied in the acute and difficult situation.

Mr AB applied to the Mental Health Review Tribunal for his discharge from section 2. His mother fought vociferously on his behalf but the section was upheld. The team considered section 3 as a management option. Mr AB's mother objected to a section 3, still thinking her son was not mentally ill. His father did appreciate that his son was unwell but would not oppose his ex-wife's opinion. He then officially relinquished his position as $\mathrm{Mr} A B$ 's nearest relative to his ex-wife. In order for a section 3 to be implemented the team investigated the possibility of displacing Mr AB's mother as nearest relative.

\section{Discussion}

Two specific points that arise from this case are concerning the rescinding the responsibilities of being the nearest relative and the displacement of the nearest relative.

Rescinding the responsibilities of being the nearest relative

Section 26 of the Mental health Act 1983 (s. 26(1)) states that the nearest relative is the first surviving person in the following list:
(a) husband or wife
(b) son or daughter
(c) father or mother
(d) brother of sister
(e) grandparent 
(f) grandchild

(g) uncle or aunt

(h) nephew or niece

"Full blood relatives take preference over half blood relatives of the same description (two brothers or two sisters) and the elder of two relatives of the same description or degree of relationship takes preference" (Bluglass, 1986). There are exceptions to this definition detailed in the Mental health Act (s26 (4-7)) but these are not relevant to this particular case.

Should a mentally ill person's nearest relative not wish to act as such, however, it is possible to rescind this responsibility in favour of another. Section 26 of the Mental Health Act 1983 states that "a person who has been identified as the patient's nearest relative can authorise any person (other than the patient or a person disqualified under sub section [5]) to perform the functions of the nearest relative. The authority can be revoked at any time. Both the authority and the revocation must be in writing."

Case. In this case authority for the mother to act as nearest relative was received in writing from the father, first by fax, and later by post.

\section{Displacement of nearest relative}

Section 29 of the Mental Health Act 1983 specifies that a county court may appoint an acting nearest relative.

There are four possible grounds on which an application can be made (s.29(3)):

"(a) that the patient has no nearest relative within the meaning of this Act, or that it is not reasonably practicable to ascertain whether he has such a relative, or who that relative is

(b) that the nearest relative of the patient is incapable of acting as such by reason of mental disorder or other illness

(c) that the nearest relative of the patient unreasonably objects to the making of an application for admission for treatment or a guardianship application in respect of the patient; or

(d) that the nearest relative of the patient has exercised without due regard to the welfare of the patient or the interests of the public his power to discharge the patient from hospital or guardianship under this Part of the Act, or is likely to do so."

Clearly, situations (a), (b) and (d) do not apply in this case. Here the difficulty lies in defining when the nearest relative "unreasonably objects" to the decisions of the health care team.

Some cases are cited in the literature to help our understanding of "unreasonable objection". (a) In the case of S. v G., Sheffield County Court [1981] J.S.W.L. 174 (Hoggett, 1990) the nearest relative was not found to be unreasonable by the court. Here the doctors recommending the section agreed that the patient was mentally ill and that he should be detained in hospital in order to protect the health and safety of the patient or the protection of other persons. The patient's father disagreed and sought opinions from two other psychiatrists. These doctors did not support the application for a section on the grounds of protection of others. The judge could therefore not rule that the father was unreasonable in his objection to the section and stated that, "It is vitally important that matters about which doctors have to be satisfied should be clearly proved".

The case illustrates how those wishing to displace the nearest relative must have very clear grounds for treatment in hospital. There was some indication from this case that during the time between the initial assessment of those recommending the section and the assessment of the second opinion doctors there had been some improvement in the patient's mental state. In $\mathbf{M r}$ AB's case it was felt that there strong, provable, and durable indications for treatment.

(b) In the case of W. $v$ L. [1974] Q.B. 711 (Hoggett, 1990) the patient was considered to be mentally ill by psychiatrists. He had threatened his wife and the baby she was expecting. His wife agreed that he needed drug treatment but disagreed that this necessitated admittance to hospital. She preferred to administer his medication at home and keep the family unit intact.

The case went to the Court of Appeal which considered that what was important was how an objectively reasonable relative would act in this situation, rather than what the wife subjectively thought to be reasonable. It was concluded that treatment at home would involve too high a risk, especially for the baby, and the wife was displaced as nearest relative.

In W. $v$ L. [1974] Q.B. 711 the grounds for treatment were strong and issues of "unreasonable objection" were considered. In this case, the wife was in agreement with the psychiatrist's diagnosis of her husband and his drug management, but only disagreed with her partner's detention under the Act. $M$. AB's mother, however, disagreed with both the diagnosis and the management, so the ward team felt that she was being neither objective nor reasonable, and that displacement would be possible if some other suitable management could not be negotiated.

Other examples cited in the literature $(\operatorname{Re} \mathrm{W}$. (An Infant) [1971] A.C. 682) not directly relevant to this case demonstrate how sometimes, two opposing views can both be judged to be "objectively reasonable". In these cases, the court must 
refrain from interfering simply because it would have chosen a different option to that of the Plaintiff (Hoggett, 1990). In another case of the relative objecting to a guardianship application (Re B. Liverpool County Court, November 29, 1985) it was held that the test of reasonableness must be judged in relation to the criteria for a guardianship application and that if there is sufficient evidence that the criteria would apply then the order for displacement would be made. The court need not be satisfied that the application for guardianship would succeed (Jones, 1991).

Under section 2(4) and section 29(4) of the Mental Health Act 1983 the period of detention under section 2 may be extended if, at the time when it would normally expire, an application under section 29 is pending. This may be important if there is any delay in hearings or appeals.

Case outcome. The team attempted to engage both $\mathrm{Mr} A B$ and his mother in all management decisions. Several family meetings involving the patient, his mother, his social worker and members of the psychiatric health team were held. When the expiry date for the section 2 arose, his mother continued to oppose a section 3, but was determined to support her son and be involved in his care. Finally it was agreed that the responsibility for the patient's care was to be shared between himself, his brother and mother. It was agreed that if $\mathrm{Mr} \mathrm{AB}$ were to become overtly disturbed that the family would take on the responsibility of care unless they wished otherwise. If this plan proved insufficient to meet the patient's needs, then it was to be revised by all those involved.
Surprisingly, the patient agreed to start taking new medication as a voluntary in-patient.

Management of uncompliant mentally ill people often involves the use of the Mental Health Act. Not infrequently nearest relatives of patients held under section are ambivalent about the restriction of liberty that has taken place. For Mr AB, despite case law supporting the use of $\mathrm{s} .29$ of the Mental Health Act 1983, it was seen that use of this risked further alienation of the nearest relative and a satisfactory compromise was sought and achieved.

\section{Acknowledgements}

We would like to thank Ms Elizabeth Knox, Solicitor and Member of the Mental Health Review Tribunal Panel for her guidance in the preparation of this report.

\section{References}

Bluglass, R. (1986) A Guide to the Mental Health Act 1983. London: Churchill Livingstone. Pp. 45.

HogGeTT, B. (1990) Mental Health Law. 3rd Edition. London: Sweet \& Maxwell. Pp 90-93.

JoNes, R. (1991) Mental Health Act Manual. 2nd Edition. London: Sweet \& Maxwell. Pp 76.

Fiona Cooke, Medical Student; Julia Watkins, Medical Student, William Osler House, John Radcliffe Hospital, Oxford OX3 6DU; and *Clive Adams, Clintcal Lecturer, University Department of Psychiatry, Warneford Hospital, Oxford OX3 7JX

*Correspondence 